\title{
Influence of Ribose $2^{\prime}$ - $O$-Methylation on $\mathrm{GpC}$ Conformation by Classical Potential Energy Calculations
}

\author{
STEVEN D. S'TELLMAN, American Health Foundation, New York, \\ New York 10019; SUSE B. BROYDE, School of Physics; and ROGER \\ M. WARTELL, Schools of Physics and Biology, Georgia Institute of \\ Technology, Atlanta, Georgia 30332
}

\section{Synopsis}

Potential energy calculations were employed to examine the effect of ribose $2^{\prime}-O$-methylation on the conformation of GpC. Minimum energy conformations and allowed conformational regions were calculated for $2^{\prime} \mathrm{MeGpC}$ and $\mathrm{Gp} 2$ 'MeC. The two lowest energy conformations of $2^{\prime} \mathrm{MeGpC}$ and $\mathrm{Gp} 2^{\prime} \mathrm{MeC}$ are similar to those of $\mathrm{GpC}$ itself. The helical RNA conformation (sugar pucker-C(3')-endo, $\omega^{\prime}$ and $\omega, g^{-} g^{-}$, bases-anti) is the global minimum, and a helix-reversing conformation with $\omega^{\prime}, \omega$ in the vicinity of $20^{\circ}, 80^{\circ}$ is next in energy. However, subtle differences between the three molecules are noted. When the substitution is on the $5^{\prime}$ ribose ( $\mathrm{Gp} 2^{\prime} \mathrm{MeC}$ ), the energy of the helical conformation is less than that of $\mathrm{GpC}$, due to favorable interactions of the added methyl group. When the substitution is at the $3^{\prime}$ ribose $\left(2^{\prime} \mathrm{MeGpC}\right)$ these stabilizing interactions are outweighed by steric restrictions, and the helical conformation is of higher energy than for GpC. Furthermore, the statistical weight of the $2^{\prime} \mathrm{MeGpC} g^{-} g^{-}$helical region is substantially less than the corresponding weight for $\mathrm{Gp} 2$ 'MeC. In addition, $2^{\prime} \mathrm{MeGpC}$ 's methoxy group is conformationally restricted to a narrow range centered at $76^{\circ}$. This group has a broadly allowed region between 50 and $175^{\circ}$ in $\mathrm{Gp} 2^{\prime} \mathrm{MeC}$. These differences occur because the appended methyl group in $2^{\prime} \mathrm{MeGpC}$ is located in the interior of the helix cylinder, as it would be in polynucleotide, while it hangs unimpeded in $\mathrm{Gp} 2$ 'MeC. These findings suggest that $2^{\prime}-O$-methylation has both stabilizing and destabilizing influences on the helical conformation of RNA. For $2^{\prime} \mathrm{MeGpC}$ the destabilizing steric hindrance imposed by the nature of the guanine base dominates.

\section{INTRODUCTION}

$2^{\prime} O$-Methylated riboses are found in ribosomal and transfer RNAs, ${ }^{1}$ and most recently have also been observed in viral RNA. ${ }^{2}$ The tRNAs are of particular interest because of the availability of crystal structure data. ${ }^{3,4}$ In the cloverleaf model of tRNAs, $2^{\prime}$-O-methylated nucleotides occur in regions which are usually not double stranded. ${ }^{1}$ However, their function is not yet understood. One possibility is that the methyl group may act as a recognition device, either in a direct steric way, or indirectly by changing the conformation in the region surrounding the modified species. ${ }^{5}$ In the monoclinic form of yeast phenylalanine tRNA, ${ }^{4}$ it has been noted that the phosphodiester backbone of the anticodon loop actually kinks at 
residues 32 and 34 , which are $2^{\prime}-O$-methyl cytidine and $2^{\prime}-O$-methyl guanosine, respectively. An understanding of the influence of ribose methylation on conformation of nucleic acid subunits should help explain its function in natural RNAs.

The conformational influence of $2^{\prime}-O$-methylation on nucleosides has been previously examined by classical potential energy calculations. Stellman et al. ${ }^{6}$ have made calculations for $2^{\prime}-O$-methyl cytidine, with particular attention to the effect of the added methyl group on the ribose pucker. These calculations produced a global minimum energy conformation, and a second conformation at $0.5 \mathrm{kcal} / \mathrm{mole}$ which were in very good agreement with the two conformers found in the crystal of $2^{\prime}-O$-methyl cytidine by Hingerty et al. ${ }^{7}$ For this nucleoside, methylation caused the $\mathrm{C}\left(2^{\prime}\right)$-endo-pucker to be preferred (although low energy $\mathrm{C}\left(3^{\prime}\right)$-endo conformations were also calculated), while cytidine itself prefers $\mathrm{C}\left(3^{\prime}\right)$-endo. The other conformational angles were not perturbed from their usual ranges. Prusiner et al. ${ }^{8}$ also found no unusual conformational angles in their calculation on $2^{\prime}-O$-methyl adenosine. Their calculations were restricted to the two sugar puckers actually found in the crystal of this molecule.

Potential energy calculations on guanylyl- $3^{\prime}, 5^{\prime}$-cytidine $(\mathrm{GpC})^{9,10}$ have delineated two low energy conformations, both with ribose pucker $\mathrm{C}\left(3^{\prime}\right)$ endo. The global minimum is like A-RNA, and has $\omega^{\prime}, \omega$ near $300^{\circ}, 280^{\circ}$. A second low energy conformation is found with $\omega^{\prime}, \omega$-near $20^{\circ}, 80^{\circ}$.

In the present work the influence of $2^{\prime}-O$-methylation on the low energy conformations of $\mathrm{GpC}$ was examined. Minimized potential energy calculations were made for $2^{\prime}-O$-methyl-GpC $\left(2^{\prime} \mathrm{MeGpC}\right)$ and $\mathrm{Gp}-2^{\prime}-O$ methyl- $\mathrm{C}\left(\mathrm{Gp} 2^{\prime} \mathrm{MeC}\right)$, and statistical weights of the low energy regions were calculated from energy contour maps. In addition, the conformation space allowed to the methoxy angle $\mathrm{m}_{1}, \mathrm{C}\left(2^{\prime}\right)-\mathrm{O}\left(2^{\prime}\right)$, (which is unique to these rare nucleotides, Fig. 1) was investigated. While the two lowest energy conformations of $\mathrm{GpC}$ are similar in the $2^{\prime}-O$-methylated derivatives, a number of subtle but potentially significant differences are noted, especially for $2^{\prime} \mathrm{MeGpC}$. The helical RNA conformation of $2^{\prime} \mathrm{MeGpC}$ has a lower statistical weight than for $\mathrm{Gp} 2 \mathrm{MeC}$. Also the methyl group itself is more restricted in $2^{\prime} \mathrm{MeGpC}$. The restrictions occur in $2^{\prime} \mathrm{MeGpC}$ because the appended methyl group is in the interior of the helix. Thus the flexibility of the molecule in this conformation is reduced. These steric constraints on the helical RNA conformation would occur in a (GC)-polymer. In $\mathrm{Gp} 2^{\prime} \mathrm{MeC}$ the methyl hangs unimpeded on the outside of the helix, an effect which would occur only at the $3^{\prime}$ end of a polymer.

\section{METHODS}

Figure 1 gives the structure and numbering scheme of $2^{\prime} \mathrm{MeGpC}$ and $\mathrm{Gp} 2^{\prime} \mathrm{MeC}$, and Table I defines the dihedral angles.

As in earlier work, ${ }^{10}$ the Scott and Scheraga equation ${ }^{11,12}$ 


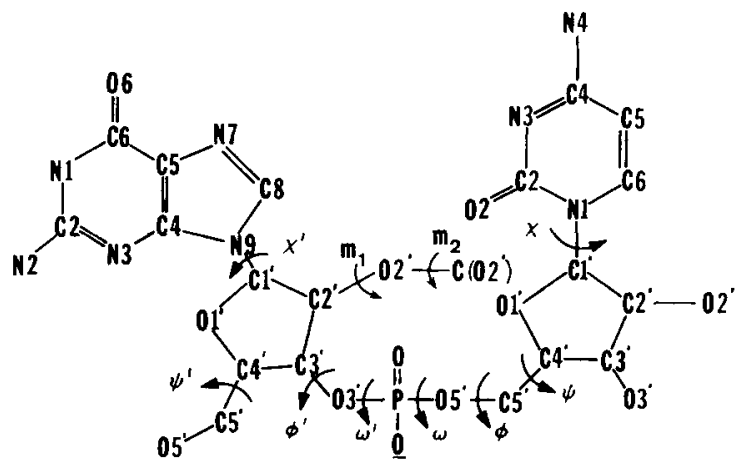

Fig. 1. Structure, numbering convention, and conformational angles of $2^{\prime} \mathrm{MeGpC}$. For $\mathrm{Gp} 2^{\prime} \mathrm{MeC}$ the methyl carbon is substituted at $\mathrm{O}\left(2^{\prime}\right)$ of the cytidine ribose.

$$
\begin{aligned}
E=\sum_{i<j} \sum\left(a_{i j} r_{i j}{ }^{-6}+b_{i j} r_{i j}{ }^{-12}\right) & +\sum_{i<j} \sum 332 q_{i} q_{j} r_{i j}{ }^{-1} \epsilon^{-1} \\
& +\sum_{k=1}^{8} \frac{V_{0, k}}{2}\left(1+\cos 3 \theta_{k}\right)
\end{aligned}
$$

was used to calculate the energy of the molecules. In this equation $r_{i j}$ is the distance in angstroms between atoms $i$ and $j, q_{i}$ is the partial charge on atom $i, \epsilon$ is the dielectric constant, $V_{0, k}$ is the barrier to internal rotation for the $k$ th dihedral angle, and $\theta_{k}$ is the value of that angle. Values for all parameters were taken from Refs. 13-15 (as before) except for the charges on the appended methyl group and the adjoining ribose. These are taken from Prusiner et al. ${ }^{8}$ The rotational barrier height for the angle $m_{1}$ (see Table I) was assigned a value of $2.0 \mathrm{kcal} / \mathrm{mole}$, as was done previously for $2^{\prime}$-O-methyl cytidine. ${ }^{6}$ The geometrical parameters employed were the same as for the earlier work on $\mathrm{GpC}$; they were taken from Arnott. ${ }^{16}$ Standard bond lengths and angles were used for the methyl group.

Using a modification of the Powell algorithm, ${ }^{17}$ the total energy was

TABLE I

Definition of Dihedral Angles for $2^{\prime} \mathrm{MeGpC}$ and $\mathrm{Gp} 2^{\prime} \mathrm{MeC}^{a}$

\begin{tabular}{ll}
\hline Angle & \multicolumn{1}{c}{ Bonds } \\
\hline$\chi^{\prime}$ & $\mathrm{O}\left(1^{\prime}\right)-\mathrm{C}\left(1^{\prime}\right)-\mathrm{N}(9)-\mathrm{C}(8)$ \\
$\psi^{\prime}$ & $\mathrm{C}\left(3^{\prime}\right)-\mathrm{C}\left(4^{\prime}\right)-\mathrm{C}\left(5^{\prime}\right)-\mathrm{O}\left(5^{\prime}\right)$ \\
$\phi^{\prime}$ & $\mathrm{P}-\mathrm{O}\left(3^{\prime}\right)-\mathrm{C}\left(3^{\prime}\right)-\mathrm{C}\left(4^{\prime}\right)$ \\
$\omega^{\prime}$ & $\mathrm{O}\left(5^{\prime}\right)-\mathrm{P}-\mathrm{O}\left(3^{\prime}\right)-\mathrm{C}\left(3^{\prime}\right)$ \\
$\omega$ & $\mathrm{C}\left(5^{\prime}\right)-\mathrm{O}\left(5^{\prime}\right)-\mathrm{P}-\mathrm{O}\left(3^{\prime}\right)$ \\
$\phi$ & $\mathrm{C}\left(4^{\prime}\right)-\mathrm{C}\left(5^{\prime}\right)-\mathrm{O}\left(5^{\prime}\right)-\mathrm{P}$ \\
$\psi$ & $\mathrm{C}\left(3^{\prime}\right)-\mathrm{C}\left(4^{\prime}\right)-\mathrm{C}\left(5^{\prime}\right)-\mathrm{O}\left(5^{\prime}\right)$ \\
$\chi$ & $\mathrm{C}(6)-\mathrm{N}(1)-\mathrm{C}\left(1^{\prime}\right)-\mathrm{O}\left(1^{\prime}\right)$ \\
$m_{1}$ & $\mathrm{C}\left(1^{\prime}\right)-\mathrm{C}\left(2^{\prime}\right)-\mathrm{O}\left(2^{\prime}\right)-\mathrm{C}\left(02^{\prime}\right)$ \\
$m_{2}$ & $\mathrm{C}\left(2^{\prime}\right)-\mathrm{O}\left(2^{\prime}\right)-\mathrm{C}\left(02^{\prime}\right)-\mathrm{H}$
\end{tabular}

a All angles A-B-C-D are measured by a clockwise rotation of $D$ with respect to A when viewed along B-C. A eclipsing $D$ is $0^{\circ}$. 
minimized as a function of eight dihedral angles-the seven backbone angles and the methoxy angle $m_{1} . \psi^{\prime}$ and $m_{2}$ (Table I) were fixed at $60^{\circ}$. The sugar puckering was set in the $\mathrm{C}\left(3^{\prime}\right)$-endo or $\mathrm{C}\left(2^{\prime}\right)$-endo conformations. The $\mathrm{C}\left(2^{\prime}\right)$-endo and $\mathrm{C}\left(3^{\prime}\right)$-endo puckers are the only ones both calculated and observed for $2^{\prime}-O$-methyl cytidine. ${ }^{6,7}$

The dihedral angles of the ribose were set at the following values (in the notation of Altona and Sundaralingam $\left.{ }^{18}\right)$ : for $\mathrm{C}\left(3^{\prime}\right)$-endo, $\theta_{1}=-38^{\circ}, \theta_{2}$ $=25^{\circ}, \theta_{3}=-1^{\circ}, \theta_{4}=-24^{\circ}, \theta_{0}=38^{\circ}$, corresponding to a pseudorotation parameter $\mathbf{P}=18^{\circ}$, and a puckering amplitude, $\theta_{m}$, of $39.8^{\circ}$. Bond angles $\mathrm{O} 1^{\prime}-\mathrm{C}^{\prime}-\mathrm{C} 2^{\prime}, \alpha_{1}$, and $\mathrm{O} 1^{\prime}-\mathrm{C} 4^{\prime}-\mathrm{C} 3^{\prime}, \alpha_{2}$ were set at 106.5 and $103.5^{\circ}$, respectively. For $\mathrm{C}\left(2^{\prime}\right)$-endo, $\theta_{1}=20^{\circ}, \theta_{2}=0^{\circ}, \theta_{3}=-21^{\circ}, \theta_{4}=32^{\circ}, \theta_{0}=-31^{\circ}$, corresponding to $\mathbf{P}=162^{\circ}, \theta_{m}=34.2^{\circ} . \quad \alpha_{1}$ and $\alpha_{2}$ were set at 106.7 and $103.1^{\circ}$. These values are not far from the energy minima calculated for unmethylated riboses by Sato. ${ }^{6,19}$

In the calculations of Sato and in those on $2^{\prime}-O$-methyl cytidine, ${ }^{6}$ the ribose pucker was a variable, and a strain component was included with the terms considered in Eq. (1) for the ribose energy. In the present work the ribose pucker was not a variable. Therefore the total within-ring ribose energy is a constant for a given pucker and is excluded, as are all interactions that are invariant with changes in dihedral angles. Overall energies for $\mathrm{C}\left(2^{\prime}\right)$-endo and $\mathrm{C}\left(3^{\prime}\right)$-endo conformations may be validly compared because the calculated ribose energies for these two puckerings are virtually equal. ${ }^{7,19}$ The methyl group has a small effect on the calculated charges of the ribose atoms. ${ }^{8}$ It thus seems likely that the $\mathrm{C}\left(2^{\prime}\right)$-endo and $\mathrm{C}\left(3^{\prime}\right)$ endo methylated riboses have similar ring energies.

Starting conformations for the dihedral angles with $\mathrm{C}\left(3^{\prime}\right)$-endo sugar puckers were the global minimum and the next lowest energy conformation of $\mathrm{GpC}$, as well as the $g^{-} t$ conformation of $\omega^{\prime}, \omega$, which has been calculated to be of low energy for other ribo sequences. ${ }^{21}$ The actual angles used are:

(1) $\chi^{\prime}=5^{\circ}$ (anti); $\phi^{\prime}=203^{\circ} ; \omega^{\prime}, \omega=298^{\circ}, 279^{\circ} ; \phi=182^{\circ} ; \psi=57^{\circ}$;

$\chi=27^{\circ}$ (anti); $m_{1}=60^{\circ}, 180^{\circ}, 300^{\circ}$ (staggered)

(2) $\chi^{\prime}=11^{\circ}$ (anti): $\phi^{\prime}=181^{\circ} ; \omega^{\prime}, \omega=16^{\circ}, 83^{\circ} ; \phi=192^{\circ} ; \psi=62^{\circ}$;

$\chi=39^{\circ}$ (anti); $m_{1}=60^{\circ}, 180^{\circ}, 300^{\circ}$ (staggered)

(3) $\chi^{\prime}=15^{\circ}$ (anti); $\phi^{\prime}=200^{\circ} ; \omega^{\prime}, \omega=290^{\circ}, 180^{\circ} ; \phi=180^{\circ}, \psi=60^{\circ}$; $\chi=15^{\circ}\left(\right.$ anti) $; m_{1}=60^{\circ}, 180^{\circ}, 300^{\circ}$ (staggered)

For $\mathrm{C}\left(2^{\prime}\right)$-endo pucker, starting conformations were:

(1) $\chi^{\prime}=55^{\circ}$ (anti); $\phi^{\prime}=200^{\circ} ; \omega^{\prime}, \omega=60^{\circ}, 60^{\circ} ; 290^{\circ}, 290^{\circ} ; 290^{\circ}, 180^{\circ}$; $\phi=180^{\circ} ; \psi=60^{\circ} ; \chi=55^{\circ}$ (anti); $m_{1}=60^{\circ}, 180^{\circ}, 300^{\circ}$ (staggered)

$\mathrm{H}\left(\mathrm{O3}^{\prime}\right)$ of cytidine, whose position is uncertain, has been set such that $\mathrm{C}\left(2^{\prime}\right)$ is trans to $\mathrm{H}\left(\mathrm{O}^{\prime}\right)$, as this setting gives the deepest global minimum. However, the energy of the $\omega^{\prime}, \omega \sim 20^{\circ}, 80^{\circ}$ minimum for $2^{\prime} \mathrm{MeGpC}$ is lower when these atoms are eclipsed, and this setting was used for that case only.

The allowed regions of $m_{1}$ were examined for both $2^{\prime} \mathrm{MeGpC}$ and $\mathrm{Gp} 2^{\prime}$ 
$\mathrm{MeC}$ by calculating the energy as a function of $m_{1}$ with the other angles fixed at either the global minimum or the next lowest energy conformation.

The $\omega^{\prime}, \omega$ conformation space for the two molecules was investigated by calculating two dimensional energy contour maps. Energies were calculated at $18^{\circ}$ intervals of each angle, for a total of 400 points. Two separate $\omega^{\prime}, \omega$ maps were constructed for each molecule with ribose pucker $\mathrm{C}\left(3^{\prime}\right)$ endo; one is for the $g^{-} g^{-}$helical RNA global minimum, and a second is for the $\omega^{\prime}, \omega \sim 20^{\circ}, 80^{\circ}$ minimum. For each map the angles other than $\omega^{\prime}, \omega$ were fixed at the values they possess at the minimum. For a given molecule, we have compared the probabilities of the low energy conformations by estimating their statistical weights from the two energy maps. This was done by adopting the formula given by Olson ${ }^{22}$ with a small modification.

$$
w_{M}=\left[\sum_{m=1}^{2} \sum_{E=1}^{5} \exp (-E / R T) A_{M, m}(E)\right] / \mathrm{Z}_{\omega^{\prime}, \omega}
$$

$w_{M}$ is defined as the statistical weight for the minimum energy region $M$ where $M$ is specified by the $\omega^{\prime}, \omega$ region, e.g., $\omega^{\prime}, \omega \sim 300^{\circ}, 300^{\circ}$. The $m$ index sums over the two $\omega^{\prime}, \omega$ maps. $E$ is the energy in $\mathrm{kcal} / \mathrm{mole}$. The sum over $E$ counts all conformational regions less than or equal to $5 \mathrm{kcal} / \mathrm{mole}$. $A_{M, m}(E)$ is the area between the $E$ and $E-1$ contours for the region $M$ on the $m$ th map. When $E=1 A_{M, m}(1)$ is the area enclosed by the $1 \mathrm{kcal}$ contour. $Z_{\omega^{\prime}, \omega}$, the partition function, is the sum of the area weighted Boltzmann factors from all energy regions less than $5 \mathrm{kcal} / \mathrm{mole}$ on both $\omega^{\prime}, \omega$ maps. (There were only two regions per map.) Areas between contours were evaluated by graphical integration. In most cases the contours rose very steeply between 1 or 2 and $5 \mathrm{kcal} / \mathrm{mole}$, and intermediate contours could not be distinguished. In that case, the area between contour intervals

TABLE II

Selected Minimum Energy Conformations of Gp2'MeC Dihedral Angles, Degrees

\begin{tabular}{|c|c|c|c|c|c|c|c|c|}
\hline$\chi^{\prime}$ & $\phi^{\prime}$ & $\omega^{\prime}$ & $\omega$ & $\phi$ & $\psi$ & $\chi$ & $m_{1}$ & $\begin{array}{c}\Delta E, \mathrm{a} \\
\mathrm{kcal} / \mathrm{mole}\end{array}$ \\
\hline \multicolumn{9}{|c|}{ Sugar Pucker C ( $\left.3^{\prime}\right)$-endo } \\
\hline 5 & 204 & 297 & 279 & 181 & 57 & 266 & 71 & 0 \\
\hline 6 & 203 & 297 & 279 & 182 & 56 & 267 & 155 & 1.0 \\
\hline 6 & 203 & 298 & 279 & 182 & 56 & 267 & 289 & 8.6 \\
\hline 19 & 183 & 10 & 92 & 189 & 64 & 21 & 72 & 2.7 \\
\hline 18 & 271 & 323 & 169 & 196 & 54 & 23 & 72 & 7.2 \\
\hline \multicolumn{9}{|c|}{ Sugar Pucker $\mathrm{C}\left(2^{\prime}\right)$-endo } \\
\hline-32 & 228 & 292 & 269 & 178 & 59 & 68 & 58 & 5.9 \\
\hline 49 & 211 & 255 & 191 & 172 & 61 & 61 & 64 & 6.6 \\
\hline 25 & 219 & 43 & 58 & 187 & 60 & 62 & 62 & 14.4 \\
\hline
\end{tabular}

a $\Delta E$ is the difference in energy between the given conformation and the global minimum. 
of $1 \mathrm{kcal} / \mathrm{mole}$ was approximated from the total area between the 2 distinguishable contours by distributing this total area uniformly among the $1 \mathrm{kcal} / \mathrm{mole}$ intervals.

\section{RESULTS}

\section{Minimum Energy Conformations of Gp2'MeC and 2' $\mathbf{M e G p C}$} ly.

Tables II and III give results for $\mathrm{Gp} 2^{\prime} \mathrm{MeC}$ and $2^{\prime} \mathrm{MeGpC}$, respective-

The global minimum for both molecules is like that of helical RNA. For $\mathrm{Gp} 2^{\prime} \mathrm{MeC}$, we find that the appended methyl group can be accommodated with virtually no changes in the backbone angles of the $\mathrm{GpC}$ helical conformation. The energy of $\mathrm{Gp} 2 / \mathrm{MeC}$ at the angles of the $\mathrm{GpC}$ helical conformation is only $0.8 \mathrm{kcal} / \mathrm{mole}$ above the global minimum of $\mathrm{Gp} 2{ }^{\prime} \mathrm{MeC}$ and $1.5 \mathrm{kcal} / \mathrm{mole}$ below the $\mathrm{GpC}$ global minimum. Thus, the global minimum energy of $\mathrm{Gp} 2^{\prime} \mathrm{MeC}$ is $2.3 \mathrm{kcal} / \mathrm{mole}$ lower than that of $\mathrm{GpC}$. For $2^{\prime} \mathrm{MeGpC}$ more extensive changes in the dihedral angles of $\mathrm{GpC}$ are needed to accommodate the methyl in the helical conformation. The initial energy is $20.1 \mathrm{kcal} / \mathrm{mole}$ above the global minimum, but minimization produced the small necessary changes in the dihedral angles which reduced the energy. The change in $\chi^{\prime}$ was responsible for most of the gain in energy. $2.4 \mathrm{kcal} /$ mole was gained in the adjustment of $m_{1}$ from its starting value of $60^{\circ}$. A further indication that the helical conformation is less favored for $2^{\prime} \mathrm{MeGpC}$ than in $\mathrm{Gp} 2^{\prime} \mathrm{MeC}$ is that the energy at the global minimum is $4.8 \mathrm{kcal} / \mathrm{mole}$ higher in $2^{\prime} \mathrm{MeGpC}$. The methoxy angle $m_{1}$ prefers the neighborhood of $70^{\circ}$ for both molecules, but for $\mathrm{Gp} 2^{\prime} \mathrm{MeC}$ there is another minimum at $155^{\circ}$ which is at only $1.0 \mathrm{kcal} / \mathrm{mole}$, and no changes in backbone are needed. For $2^{\prime} \mathrm{MeGpC}$, on the other hand, the energy of this second minimum is at 6.8

TABLE III

Selected Minimum Energy Conformations of 2'MeGpC Dihedral Angles, Degrees

\begin{tabular}{|c|c|c|c|c|c|c|c|c|}
\hline$\chi^{\prime}$ & $\phi^{\prime}$ & $\omega^{\prime}$ & $\omega$ & $\phi$ & $\psi$ & $x$ & $m_{1}$ & $\begin{array}{c}\Delta E,^{\mathrm{a}} \\
\mathrm{kcal} / \mathrm{mole}\end{array}$ \\
\hline & & & \multicolumn{6}{|c|}{ Sugar Pucker $\mathrm{C}\left(3^{\prime}\right)$-endo } \\
\hline-4 & 204 & 301 & 271 & 193 & 54 & 28 & 76 & 0 \\
\hline-14 & 259 & 268 & 289 & 148 & 55 & 26 & 151 & 6.8 \\
\hline 6 & 202 & 298 & 276 & 183 & 58 & 27 & 313 & 63.9 \\
\hline 13 & 176 & 17 & 83 & 192 & 61 & 19 & 77 & 1.2 \\
\hline \multirow[t]{2}{*}{28} & 262 & 316 & 158 & 214 & 53 & 19 & 77 & 7.7 \\
\hline & & & \multicolumn{6}{|c|}{ Sugar Pucker C(2')-endo } \\
\hline 49 & 198 & 254 & 194 & 173 & 61 & 58 & 67 & 4.5 \\
\hline 38 & 276 & 280 & 289 & 169 & 56 & 65 & 176 & 7.4 \\
\hline 39 & 268 & 59 & 89 & 172 & 61 & 40 & 175 & 10.5 \\
\hline
\end{tabular}

a $\Delta E$ is the difference in energy between the given conformation and the global minimum. 


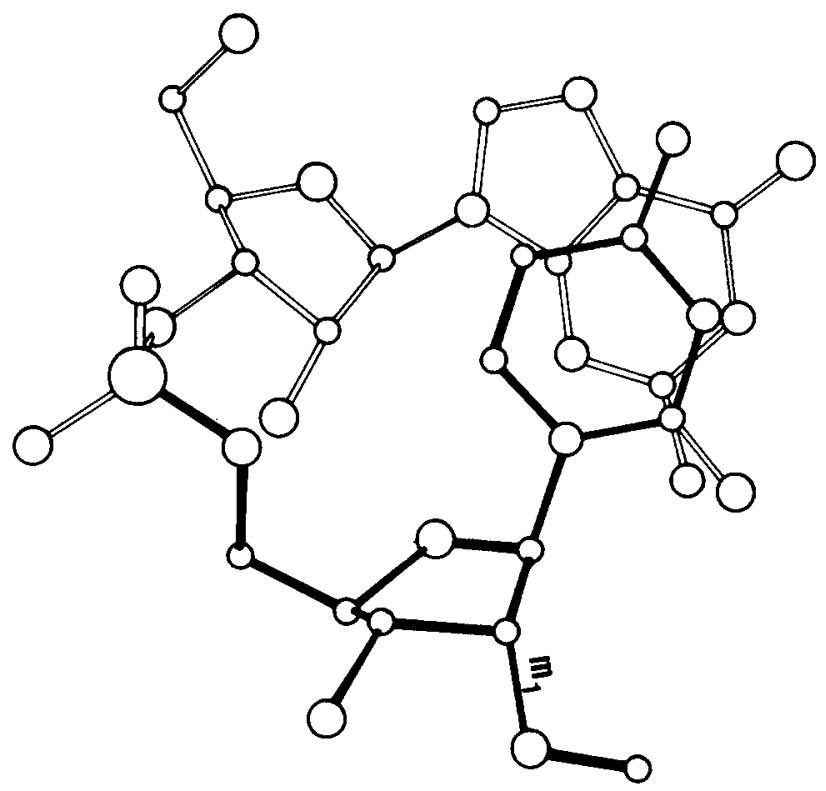

$\bigcirc p$

$\bigcirc 0$

O N

O C

(a)

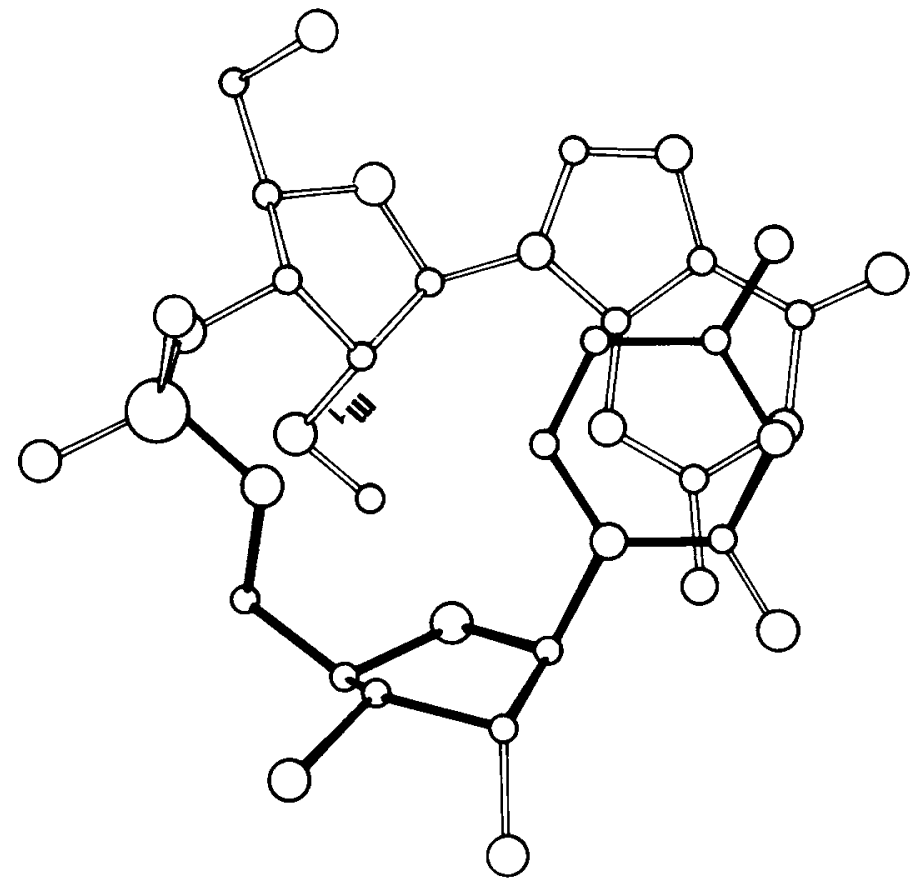

$\bigcirc p$

$\bigcirc 0$

O N

O C

(b)

Fig. 2. (a) $\mathrm{Gp} 2^{\prime} \mathrm{MeC}$ in its helical RNA global minimum energy conformation (see Table II). (b) 2'MeGpC in its helical RNA global minimum energy conformation (see Table III). 
$\mathrm{kcal} / \mathrm{mole}$, and rather substantial changes in backbone angles occur. The $300^{\circ}$ region is totally inaccessible for this molecule (greater than $60 \mathrm{kcal} /$ mole), but it lies at $8.6 \mathrm{kcal} / \mathrm{mole}$ for $\mathrm{Gp2} / \mathrm{MeC}$.

The next minimum has $\omega^{\prime}, \omega$ near $20^{\circ}, 80^{\circ}$. It occurs at $2.7 \mathrm{kcal} / \mathrm{mole}$ for $\mathrm{Gp2} 2^{\prime} \mathrm{MeC}$, while it is at $1.2 \mathrm{kcal} / \mathrm{mole}$ for $2^{\prime} \mathrm{MeGpC}$. The favored regions of $m_{1}$ follow the same pattern as the helical RNA conformation; results in Tables II and III are given only for the lowest energy of $m_{1}$.

The $\mathrm{C}\left(3^{\prime}\right)$-endo $\mathrm{g}^{-} t$ minimum energy conformers are above $7 \mathrm{kcal} / \mathrm{mole}$ and only the lowest energy of $m_{1}$ is shown.

As with $\mathrm{GpC}$ itself, the $\mathrm{C}\left(2^{\prime}\right)$-endo conformations are all of high energy; the $\mathrm{B}$ form conformation is at $5.9 \mathrm{kcal} / \mathrm{mole}$ for $\mathrm{Gp} 2^{\prime} \mathrm{MeC}$ and $7.4 \mathrm{kcal} / \mathrm{mole}$ for $2^{\prime} \mathrm{MeGpC}$. Results are again given only for the lowest energy of $m_{1}$.

Figures $2 \mathrm{a}$ and b show $\mathrm{Gp} 2^{\prime} \mathrm{MeC}$ and $2^{\prime} \mathrm{MeGpC}$ at their helical global minima. It is apparent that the methoxy is crowded into the inside of the helix in $2^{\prime} \mathrm{MeGpC}$, as it would be in a polynucleotide, while it hangs on the outside of $\mathrm{Gp}^{\prime} \mathrm{MeC}$. This explains why delicate adjustment in the dihedral angles is needed for the group to be accommodated in the helical RNA conformation of $2^{\prime} \mathrm{MeGpC}$. It causes the methoxy to be conformationally more restricted in $2^{\prime} \mathrm{MeGpC}$ than $\mathrm{Gp} 2^{\prime} \mathrm{MeC}$. The stacking of bases is slightly less for $2^{\prime} \mathrm{MeGpC}$ than for $\mathrm{Gp} 2^{\prime} \mathrm{MeC}$.

\section{Energy Maps for Methoxy Angle, $\mathrm{C}\left(2^{\prime}\right)-\mathrm{O}\left(2^{\prime}\right), \mathrm{m}_{1}$}

Figure $3 a$ and $b$ shows the energy of $\mathrm{Gp} 2^{\prime} \mathrm{MeC}$ and $2^{\prime} \mathrm{MeGpC}$, respectively, as a function of $m_{1}$. Other angles were fixed at the values they possess at their global minima. Results are similar for the $20^{\circ}, 80^{\circ}$ minima of $\omega^{\prime}, \omega$, and are not shown. For $\mathrm{Gp} 2^{\prime} \mathrm{MeC}$ the entire region between 50 and $175^{\circ}$ is of low energy, with the global minimum at $71^{\circ}$. The other minima are at 155 and $289^{\circ}$, the latter however being of high energy. With $2^{\prime}$ $\mathrm{MeGpC}$, when the other angles are fixed at the helical global minimum, only one narrow low energy region, centered at $75^{\circ}$ is seen. When the backbone angles are fixed at the helical minimum corresponding to $m_{1}=151^{\circ}$ (see Table III), a sharp, two pronged energy map is produced with a minimum at $75^{\circ}$ and a second but considerably higher energy minimum at $151^{\circ}$. It is clear from the above that $m_{1}$ is much more conformationally restricted in $2^{\prime} \mathrm{MeGpC}$ than in $\mathrm{Gp} 2^{\prime} \mathrm{MeC}$. In the former case only one narrow conformation range is favored, while for $\mathrm{Gp2}{ }^{\prime} \mathrm{MeC}$ a broad range encompassing two minima and more than $100^{\circ}$ is found.

\section{Energy Contour Maps for $\omega^{\prime}, \omega$}

Figures 4 and 5 show low energy contours of $\omega^{\prime}$ and $\omega$ for $\mathrm{Gp} 2^{\prime} \mathrm{MeC}$ and $2^{\prime} \mathrm{MeGpC}$, respectively. For $2^{\prime} \mathrm{MeGpC}$ it was not possible to choose one set of fixed values for the other angles that would accurately show the energy relationships between the two low energy regions. For this reason two 


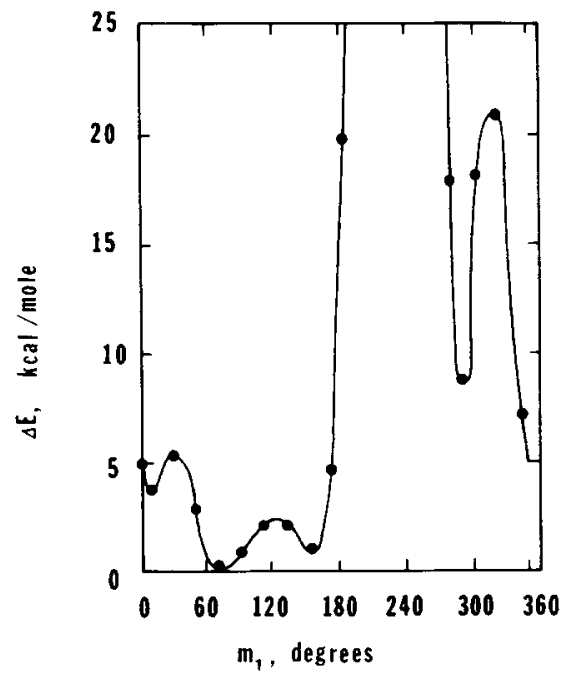

(a)

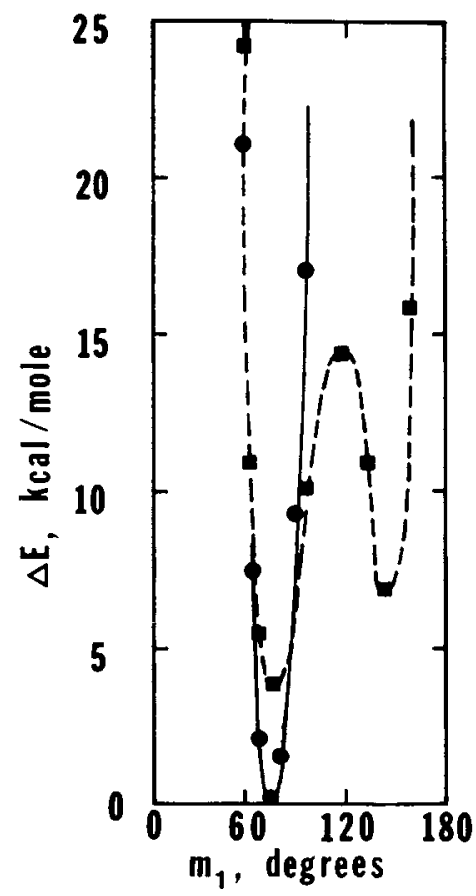

(b)

Fig. 3. (a). Energy of $\mathrm{Gp} 2^{\prime} \mathrm{MeC}$ as a function of $\mathrm{C}\left(2^{\prime}\right)-\mathrm{O}\left(2^{\prime}\right)$ angle $m_{1}$. Other angles set at global minimum (see Table II). (b) Energy of $2^{\prime}$ meGpC as a function of $\mathrm{C}\left(2^{\prime}\right)-\mathrm{O}\left(2^{\prime}\right)$ angle $m_{1}$. Other angles set at (-) helical RNA global minimum or (- - -) helical minimum for $m_{1}$ $=151^{\circ}$ (see Table III). 


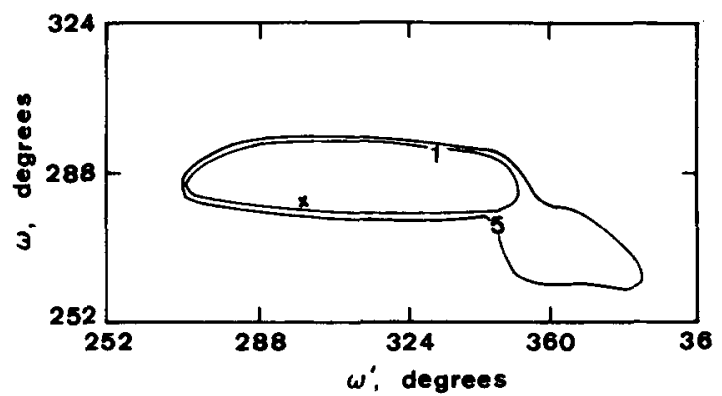

(a)

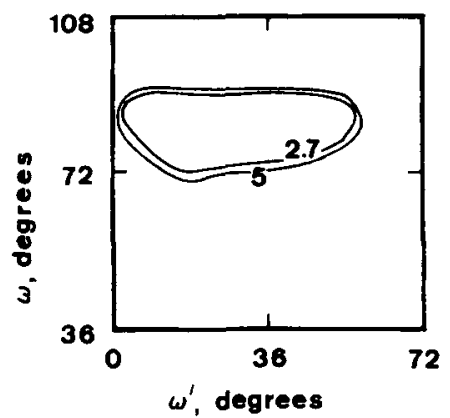

(b)

Fig. 4. Low energy contours of $\omega^{\prime}, \omega$ for $\mathrm{Gp} 2^{\prime} \mathrm{MeC}$ : (a) other angles fixed at helical RNA global minimum; (b) other angles fixed at second lowest energy minimum (see Table II).

separate $\omega^{\prime}, \omega$ maps were drawn. Angles other than $\omega^{\prime}, \omega$ were fixed at the minima of one of the two low energy regions (see Tables II and III). The same procedure was used for $\mathrm{Gp} 2^{\prime} \mathrm{MeC}$. Under these circumstances, the effective statistical weight of the $20^{\circ}, 80^{\circ}$ region in the map where the helical RNA angles were employed was less than $0.1 \%$. The same is true of the statistical weight of the $g^{-} g^{-}$region in the map showing the conformation space near $20^{\circ}, 80^{\circ}$. Contour energies are relative to the global minimum of each molecule. We note that the helical RNA conformation occupies a much smaller area within the $1 \mathrm{kcal} /$ mole contour for $2^{\prime} \mathrm{MeGpC}$ than for Gp2'MeC. Statistical weights were calculated using Eq. (2), and are given in Table IV. The helical RNA-like conformation has a statistical weight of 0.96 for $\mathrm{Gp} 2^{\prime} \mathrm{MeC}$, while the statistical weight of this helical region is reduced to 0.59 in $2^{\prime} \mathrm{MeGpC}$.

\section{DISCUSSION}

\section{Comparison of Conformations of $\mathbf{2}^{\prime} \mathrm{MeGpC}, \mathrm{Gp2} \mathbf{M e C}^{\prime}$, and $\mathrm{GpC}$}

The influence of $2^{\prime}-O$-methylation on the $\mathrm{GpC}$ conformation depends on whether this group is appended to the $3^{\prime}$ or the $5^{\prime}$ ribose. At first sight 


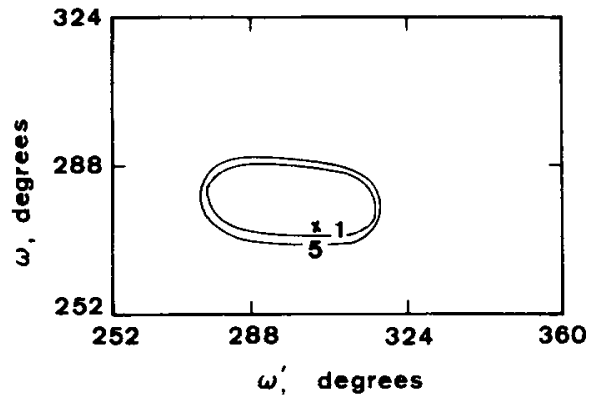

(a)

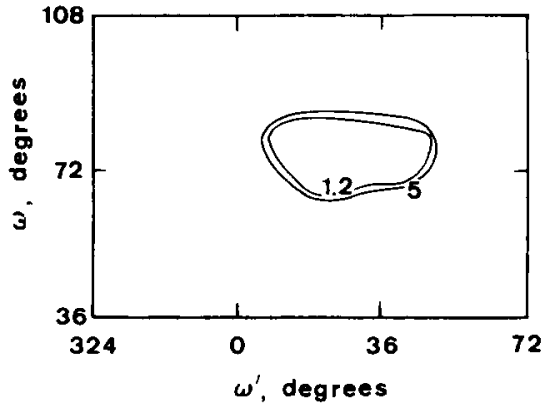

(b)

Fig. 5. Low energy contours of $\omega^{\prime}, \omega$ for $2^{\prime} \mathrm{MeGpC}$ : (a) other angles fixed at helical RNA global minimum; (b) other angles fixed at second lowest energy minimum (see Table III).

it appears that the methyl substitution has little influence on $\mathrm{GpC}$, since very similar minima are obtained for the methylated derivatives and $\mathrm{GpC}$ itself. On closer examination, however, differences emerge. The differences between $\mathrm{GpC}$ and $\mathrm{Gp} 2^{\prime} \mathrm{MeC}$ are small. The most notable difference is that the energy at the global minimum is $2.3 \mathrm{kcal} / \mathrm{mole}$ lower in $\mathrm{Gp} 2{ }^{\prime} \mathrm{MeC}$ than in $\mathrm{GpC}$. The $\mathrm{Gp} 2^{\prime} \mathrm{MeC}$ helix is probably stabilized by attractive van der Waals interactions of the methyl with cytosine, and the adjoining ribose. In $2^{\prime} \mathrm{MeGpC}$ the stabilizing interactions of the methyl are outweighed by other effects. These are manifested in the following ways: (1) When $2^{\prime}$ $\mathrm{MeGpC}$ is set at the helical RNA global minimum of $\mathrm{GpC}$, its energy prior to minimization is $20.1 \mathrm{kcal} / \mathrm{mole}$ while $\mathrm{Gp} 2{ }^{\prime} \mathrm{MeC}$ has an energy of only 0.8

TABLE IV

Statistical Weights for Low Energy Conformational Regions of 2'MeGpC and Gp2'MeC

\begin{tabular}{lcc}
\hline & $\begin{array}{c}\text { Conformational Region, } \\
\omega^{\prime}, \omega\end{array}$ & Statistical Weight \\
\hline $2^{\prime} \mathrm{MeGpC}$ & $301^{\circ}, 271^{\circ}$ & 0.59 \\
& $17^{\circ}, 83^{\circ}$ & 0.41 \\
$\mathrm{Gp2} 2^{\prime} \mathrm{MeC}$ & $297^{\circ}, 279^{\circ}$ & 0.96 \\
& $10^{\circ}, 92^{\circ}$ & 0.04 \\
\hline
\end{tabular}


$\mathrm{kcal} / \mathrm{mole}$ in the same conformation. Thus, adjustment in the dihedral angles from the $\mathrm{GpC}$ global minimum is needed to accommodate the methyl in the helical conformation of 2 MeGpC. A change in the glycosidic torsion angle $\chi^{\prime}$ alleviates a steric repulsion between guanosine N3 and a methyl hydrogen. This accounts for a large part of the energy gain. With $\mathrm{Gp} 2^{\prime}$ $\mathrm{MeC}$, on the other hand, only slight adjustment of the methoxy is needed. (2) The conformation space accessible to the methoxy angle $m_{1}$ is considerably more restricted in $2^{\prime} \mathrm{MeGpC}$ than in $\mathrm{Gp} 2^{\prime} \mathrm{MeC}$. (3) The statistical weight of the helical conformation is reduced from 0.96 in $\mathrm{Gp} 2^{\prime} \mathrm{MeC}$ to 0.59 in $2^{\prime} \mathrm{MeGpC}$. Stated in a possibly more significant way, the statistical weight of the "helix reversing" conformation ${ }^{23}\left(\omega^{\prime} \omega \sim 20^{\circ}, 80^{\circ}\right)$ is increased from 0.04 to 0.41 . (4) The absolute energy of the helical RNA conformation of $2^{\prime} \mathrm{MeGpC}$ is $2.5 \mathrm{kcal} / \mathrm{mole}$ greater than that of $\mathrm{GpC}$. These are all reflections of the crowding produced by the methyl when located in the interior of the $2^{\prime} \mathrm{MeGpC}$ helix.

\section{Ribose Pucker}

$2^{\prime}$ - $O$-Methylation of cytidine causes the $\mathrm{C}\left(2^{\prime}\right)$-endo pucker to be preferred over $\mathrm{C}\left(3^{\prime}\right)$-endo in $2^{\prime}$ - $O$-methyl cytidine. ${ }^{7}$ However, in larger structures, such as $\mathrm{GpC}^{20}$ and its methylated derivatives, $\mathrm{C}\left(2^{\prime}\right)$-endo is not of low energy. Solution studies of polymers are consistent with this observation. Nmr studies of poly(r2'Me-cytidilic acid) ${ }^{24}$ indicate that this polymer is in the $\mathrm{C}\left(3^{\prime}\right)$-endo conformation in solution. Furthermore, Bobst et al. ${ }^{25}$ have ruled out a major change in sugar conformation on $2^{\prime}-O$ methylation of both riboses in ApA, which is $\mathrm{C}\left(3^{\prime}\right)$-endo in solution. Sarma (private communication) has also come to this conclusion for 2 MeApA. Thus, the $\mathrm{C}\left(3^{\prime}\right)$-endo pucker preferred by common ribonucleotides is retained on $2^{\prime}-O$-methylation.

\section{Conformations of Methoxy Angle $m_{1}$}

Allowed conformations of the methoxy angle $\mathrm{O}\left(2^{\prime}\right)-\mathrm{C}\left(2^{\prime}\right)$ calculated in this work (Fig. 3) are in good agreement with the calculations of Prusiner et al. ${ }^{8}$ for the $\mathrm{C}\left(3^{\prime}\right)$-endo conformation of $2^{\prime}$ - $O$-methyl adenosine $3^{\prime}$ phosphate and $2^{\prime}-O$-methyl adenosine $3^{\prime}, 5^{\prime}$ diphosphate. For the $5^{\prime}$ nucleotide they calculate a permitted range of $80-160^{\circ}$, which may be compared with the minima at 71 and $154^{\circ}$ calculated here for $\mathrm{Gp} 2^{\prime} \mathrm{MeC}$. The latter minimum is just $1.0^{\prime} \mathrm{kcal} / \mathrm{mole}$ higher in energy than the former, and the two are separated by a barrier of only 1 to $2 \mathrm{kcal} / \mathrm{mole}$ (depending on direction). It is interesting to note that both these conformational regions occur in the crystal of $2^{\prime}-O$-methyl cytidine. ${ }^{7}$ In the presence of the $3^{\prime}$ phosphate, Prusiner et al. find the methoxy to be more restricted, within the $90-130^{\circ}$ range. We find a similar restriction for $2^{\prime} \mathrm{MeGpC}$. The minima are at 76 and $151^{\circ}$, but the latter minimum is at $6.8 \mathrm{kcal} / \mathrm{mole}$. Furthermore, con- 
siderable adjustment in the backbone angles is needed to accommodate the higher energy conformation, and a barrier of $7-10 \mathrm{kcal} / \mathrm{mole}$ separates the two minima.

\section{Comparison with Studies of Base Stacking in Solution}

The influence of 2 - $O$-methylation on the extent of stacking and the stability of stacked structures in solution has been investigated by $\mathrm{nmr}$, ORD, and CD spectroscopy, for dinucleoside phosphates (Refs. 26-28 and R. Sarma, personal communication) and for poly(r2'Me adenylic acid $)^{29}$ and poly(r2' $\mathrm{Me}$ cytidylic acid) ${ }^{24}$ In these studies, stacking is implicitly equated with the helical RNA conformation. However, other stacked conformations are of low energy, notably the "helix-reversing" conformation, so that base stacking need not be correlated with the RNA helix.

In general, there is no profound difference between the spectra of the modified and the unmodified species for dinucleoside phosphates. This agrees with the similar helical global minima calculated here for $\mathrm{GpC}$ and its two methylated derivatives. Stacking appears to be enhanced or diminished, to a small extent, depending on sequence, with the substituted adenosines having a tendency to reduce stacking. The ORD of GpC and $2^{\prime} \mathrm{MeGpC}$ were compared by Singh and Hillier ${ }^{27}$ at room temperature. They are of similar form, with a slightly diminished amplitude in the substituted derivative at $\mathrm{pH} 7$. This suggested a small decrease in stacking, which also agrees with our findings. Warshaw and Cantor $^{26}$ found the CD spectra of $2^{\prime} \mathrm{MeCpC}$ and $\mathrm{CpC}$ to be almost identical, indicating a similar stacking geometry. However, the temperature dependence of the spectra showed a more stable structure for the methylated derivative. We find a less stable helical structure for methylation at the $3^{\prime}$ ribose. Possibly the smaller $3^{\prime}$ cytidine offers less steric hindrance, so that the favorable interactions of the methyl group overcome the steric restrictions which predominate in $2^{\prime} \mathrm{MeGpC}$. Drake et al. ${ }^{28}$ studied the $\mathrm{CD}$ spectra and their temperature dependence on $133^{\prime}$ substituted dinucleoside phosphates, as well as three that were substituted at both riboses. (They did not examine GpC derivatives.) They drew the general conclusion that stacking is enhanced by the modification, except for adenosines, but we believe their data can also be interpreted as showing that the stacked structure may be stabilized or destabilized by the substitution without appreciable change in the base overlap. Drake et al. ${ }^{28}$ observed that substitution at the $5^{\prime}$ ribose has a smaller effect than at the $3^{\prime}$ ribose unit, which agrees with our results. In general, it appears that a competition exists between the stabilizing interactions of the methyl group and its destabilizing effect due to steric hindrance. The bases surrounding the methyl group may determine which prevails in a polymer.

The authors thank the Computer Center and the School of Physics of the Georgia Institute of Technology for a grant of computer time. They are grateful to Prof. Ian Gatland, School of Physics, Georgia Institute of Technology, for help with the computer. They also thank 
Dr. Brian Hingerty, MRC Laboratory of Molecular Biology, Cambridge, England, for helpful comments. Support for this work was received under National Institutes of Health Grant GM-22765-01 and is gratefully acknowledged.

\section{References}

1. Barrel, B. \& Clark, B. (1974) Handbook of Nucleic Acid Sequences, Joynson-Bruvvers Ltd., Eynsham, Oxford.

2. Furuichi, Y., Morgan, M., Muthukrishnan, S. \& Shatkin, A. J. (1975) Proc. Nat. Acad. Sci. 72, 362 .

3. Kim, S., Suddath, F., Quigley, G., McPherson, A., Sussman, J., Wang, A., Seeman, N. \& Rich, A. (1974) Science 185, 435-440.

4. Robertus, J., Ladner, J., Finch, J., Rhodes, D., Brown, R., Clark, B. \& Klug, A. (1974) Nature 250, 546-551.

5. Hall, R. (1971) The Modified Nucleosides in Nucleic Acids, Columbia University Press, New York.

6. Stellman, S., Hingerty, B., Broyde, S. \& Langridge, R. (1975) Biopolymers 14, 20492060 .

7. Hingerty, G., Bond, P., Langridge, R. \& Rottman, F. (1974) Biochem. Biophys. Res. Commun. 61, 875-881.

8. Prusiner, P., Yathindra, N. \& Sundaralingam, M. (1974) Biochim. Biophys. Acta 366, 115-123.

9. Stellman, S., Hingerty, B., Broyde, S., Subramanian, E., Sato, T. \& Langridge, R. (1973) Biopolymers 12, 2731-2750.

10. Broyde, S., Stellman, S., Hingerty, B. \& Langridge, R. (1974) Biopolymers 13, 12431259.

11. Scott, R. \& Scheraga, H. (1966) J. Chem. Phys. 44, 3054-3069.

12. Scott, R. \& Scheraga, H. (1966) J. Chem. Phys. 45, 2091-3101.

13. Lakshminarayanan, A. \& Sasisekharan, V. (1969) Biopolymers 8, 475-480.

14. Lakshminarayanan, A. \& Sasisekharan, V. (1969) Biopolymers 8, 489-503.

15. Renugopalakrishnan, V., Lakshminarayanan, A. \& Sasisekharan, V. (1971) Biopolymers $10,1159-1167$.

16. Arnott, S., Dover, S. \& Wonacott, A., (1969) Acta. Cryst. B25, 2192-2206.

17. Powell, M. (1964) Computer J. 7, 155-159.

18. Altona, C. \& Sundaralingam, M. (1972) J. Amer. Chem. Soc. 94, 8205-8212.

19. Sasisekharan, V. (1973) in Conformation of Biological Molecules and Polymers, Jerusalem Symposia on Quantum Chemistry and Biochemistry, V, pp. 247-260.

20. Broyde, S., Stellman, S. \& Wartell, R. (1975) Biopolymers 14, 2625-2637.

21. Broyde, S., Wartell, R., Stellman, S., Hingerty B., \& Langridge, R. (1975) Biopolymers 14, 1597-1613.

22. Olson, W. (1975) Biopolymers 14, 1775-1795.

23. Kim, S. H., Berman, H., Seeman, N. \& Newton, M. (1973) Acta Cryst. B29, 703.

24. Alderfer, J., Tazawa, I., Tazawa, S. \& Ts'o, P. O. P. (1975) Biophys. J. 15, 299.

25. Bobst, A. M., Rottman, F. \& Cerutti, P. (1969) J. Amer. Chem. Soc. 91, 4603-4604.

26. Warshaw, M. M. \& Cantor, C. R. (1970) Biopolymers 9, 1079-1103.

27. Singh, H. \& Hillier, B. (1971) Biopolymers 10, 2445-2457.

28. Drake, A. F., Mason, S. F. \& Trim, A. R. (1974) J. Mol. Biol. 86, 727-739.

29. Alderfer, J., Tazawa, I., Tazawa, S., \& Ts'o, P. O. P. (1974) Biochemistry 13, 16151622.

Received October 10, 1975

Returned for revision December 8, 1975

Accepted March 24, 1975 